\title{
Vertical distraction osteogenesis of frontal segment and platelet-rich plasma in the edentulous mandible
}

\author{
T. Feltsan, J. Mracna, P. Stanko \\ Department of Stomatology and Maxillofacial Surgery, Faculty of Medicine, Comenius University, \\ and St. Elizabeth Institute of Oncology, Bratislava, Slovakia. tfeltsan@ousa.sk
}

\begin{abstract}
In patients with atrophy of the alveolar ridge of classes V and VI according to Cawood and Howell, the distraction osteogenesis (DO) is the only possibility of reconstruction connected with subsequent dental implants. This method was introduced by llizarov (1989), a Russian doctor. In the past few years, the distraction devices have undergone several changes and technical improvements. The usage of platelet-rich plasma (PRP) and autologous bone-platelet gel (ABPG) serving as the source of growth factors is considered a significant progress. The increase in the level of growth factors leads to new bone formation and in soft tissues enhances the healing around the bone and bone wound, lowers the risk of postoperative complications such as pain, swelling and bleeding as well as enables fast placement of implants (Ref. 19). Full Text in PDF www.elis.sk. Key words: distraction osteogenesis, platelet rich plasma (PRP), autologous bone-platelet gel (ABPG), growth factors.
\end{abstract}

The possibility of bone tension was described by Covil (1904) and Abbot (1972) (1) who presented the possibility of femur extension. Ilizarov, a Russian orthopaedist $(2,3)$ developed the distraction osteogenesis theory (DO) and this theory has become acceptable in the field of orthopaedics and traumatology. Distraction osteogenesis is a biological process of new bone formation between bone segments gradually separated by incremental traction. This stimulus activates the forces of spontaneous healing and continuously creates new callus and bone extension. Distraction at a slow rate with small and frequent steps is efficient for callus formation. Fluent formation brings optimal stimulation. It enables to make exact changes in the size and form of bone. The significant advantage of this technique lies in simultaneous augmentation of soft tissue (histogenesis) (4). Slow changes enable better the soft tissue to adapt and are considered beneficial while this technique prevents recidivation. In the past years, consistent miniaturization of disctraction devices enables the usage of distraction osteogenesis in cases of mandibular atrophy reconstruction of the alveolar ridge. It is common ín patients with severe bone atrophy of classes $\mathrm{V}$ and VI according to Cawood and Howell (5).

First experiments of mandibular distraction in maxillofacial area were described by Chin and Toth (6), who used the DO technique followed by placement of implants to a reconstructed bone after the successful distraction of segments. In 1998 Marx (7) proposed the bone regeneration model observed in autologous

Department of Stomatology and Maxillofacial Surgery, Faculty of Medicine, Comenius University, and St. Elizabeth Institute of Oncology, Bratislava, Slovakia

Address for correspondence: T. Feltsam, MD, Dept of Stomatology and Maxillofacial Surgery, Faculty of Medicine, Comenius University, and St. Elizabeth Institute of Oncology, Heydukova 10, SK-812 50 Bratislava, Slovakia.

Phone: +421.2 .52933167$ bone transplants while this model helped Robiony to use ABPG (autologous bone-platelet gel) as a source of growth factors, and matrix for new bone regeneration in DO (4). Platelet-rich plasma (PRP) contained within ABPG is the source of growth factors that initiate the bone regeneration and soft-tissue healing $(7,8,9)$.

\section{Surgical procedures}

The operation is performed under general anaesthesia. One day before the surgical intervention, all patients receive antibiotic medication consisting of Clyndamicinum in eight-hour intervals. The operation site is exposed by vestibular incision followed by careful elevation of the mucoperiosteum flap to avoid injury to the mental nerve. This incision is believed to hold the advantage over a mid-crestal incision in preserving blood supply for the crestal aspects of the transport bone segment. Before performing osteotomies, the distraction device is placed to create a mark for screws in order to achieve the correct position and to avoid the complicating fracture of distraction fragments. The osteotomies are performed using the piezoelectric bundle. When compared to classical devices, this device is greatly beneficial for both patient and surgeon. This minimally invasive surgery forces the healing as well as reduces pain and swelling. This technique is connected with blood reduction, soft-tissue protection during the operation and optimises the surgical results. As the shape of the transport disk defines the final bone shape and thus as well the aesthetical results, the osteotomy is modified for particular anatomic location. For the posterior mandible, a trapezoidal or an L-shaped segment with the vertical limb placed anteriorly is performed. Once osteotomy is completed, the distractor plates are fixed positioning the distractor device with the activation screw while the gap is filled with ABPG and covered with absorbable material. Finally, the mucosa is sutured and 5 to $10 \mathrm{ml}$ of platelet-rich plasma (PRP) is applied. 


\section{Distraction protocol}

After 5-7 days of latency period to allow the formation of a reparative callus, we activate the distractor by turning the screw at a rate of $1 \mathrm{~mm} /$ day until the desired lengthening is achieved; the distraction period is approximately ten days. After a 60-day period of consolidation, the distractor is removed. This period is connected with new bone formation and mineralization as could be seen through histological procedures and X-ray pictures. Periapical and panoramic radiographs are obtained at the end of active disctraction. After this period, the disctractor is removed and the implants are placed.

\section{Discussion and conclusion}

In the past few years the DO is recommended to restore the atrophic mandible $(11,12,13)$. DO is a vascular-dependent process and requires an adequate blood supply, however severe atrophy, (Cawood and Howell classes V and VI), is the main problem. Robiony recommends the distraction after a fifteen-day latency period because the complete revascularization of the callus is observed not earlier than in 14 days. Additionally, after the use of PRP and ABPG monthly and after the end of distraction, the angiogenesis in the site of callus (4) is evidenced by Dopler USG examination The evidence of new bone formation in a sufficient phase of mineralization after a latency period (60) ensures the implant's primary stability $(15,16,17,18)$.

The use of PRP and ABPG enrich the improvement of DO. Specific studies of PRP identified at least three platelet-derived growth factors in alpha granular thrombocytes derivate from derived growth factor (PDGF), transmuted growth factor $\beta_{1}$ (TGF- $\beta_{1}$ ) and transmuted growth factor $\beta_{2}$ (TGF- $\left.\beta_{2}\right)$. Other surveys show the presence of insulin as a growth factor I (IGF-I) (19). The specific functions of growth factors include activation of endothelial, epithelial and epidermal regeneration, stimulate angiogenesis, support collagen synthesis, enhance the stability of regenerated tissue, are haemostatic, organize the blood haematoma, reduce the postoperative oedema, lessen the pain and reduce the consumption of analgesic drugs in the postoperative period, activate the deposition of extracellular matrix and the healing of the wound.

Amir evaluated the impact of distraction of $1 \mathrm{~mm} /$ day and the length of consolidation period of new bone-formation quality and wound closure (10). He concludes that in elderly patients, the distraction rate of $0.5 \mathrm{~mm} /$ day results in faster osteogenesis in the distraction gap than that at rate of $1 \mathrm{~mm} /$ day. A minimum of ten days of neutrofixation without using PRP and ABPR seems to be needed to close the 10-mm gap after cessation of distraction. Based on micro-CT histomorphometric procedures, a longer bone trabecular length and small assessment of the bone formation volume were measured in $0.5 \mathrm{~mm} /$ day group compared to 1 $\mathrm{mm}$ /day group.

An absolute building of alveolar ridge consists of osteoplasty reconstruction and modelling the base and vestibulum. Thus the DO should be considered an effective and predictable procedure in osteoplasty.

\section{References}

1. Zajko J, Hirjak D. Methods of augmentation as a part of dental implantology. Choroby hlavy a krku, 2005; 15 (1): 9-14.

2. Ilizarov GA. The tension-stress effect on the genesis and growth of tissures. Part I. The influence of stability of fixation and soft-tissue preservation. Clin Orthop 1989; 238: 249-281.

3. Ilizarov GA. The tension-stress effect on the genesis and growth of tissures. Part II. The influence of the rate and frequency of distraction. Clin Orthop 1989; 239: 263-285.

4. Robiony M, Polini F, Costa F et al. Vertical augmentation in severe atrophic mandible: osteogenesis distraction and platelet-rich plasma (PRP). Riv Ital Chir Maxillo-Fac 2001; 12: 3-7

5. Cawood JI, Howell RA. Reconstructive preprosthetic surgery. I. Anatomical consideration. Int J Oral Maxillofac Surg 1991; 20: 75-82.

6. Chin M, Toth BA. Distraction osteogenesis in maxillofacial surgery using internal devices: review of five case. J Oral Maxillofac Surg1996; 54: 45-53.

7. Marx RE, Carlson ER, Eichstaedt RM, Schimmele SR, Strauss JE, Georgeff KR. Platelet-rich plasma: growth factor enhancement for bone grafts. Oral Surg Oral Med Oral Pathol Oral Radiol Endod 1998; 85: 638-646.

8. Ghurani R, Marx R, Monteleone K. Healing Enhancement of Skin Graft Donor Sites With Platelet-Rich Plasma, Oral Abstract Session 6, American Academy of Oral Maxillofacial Surgery. September 2000.

9. Cohen I. K, Diegelman R, Yager D, Waren I et al. Wound care and wound healing. 263-296. In: Seymore I, Schwartz S, Shires T, Spencer R, Galloway A (Eds). Principles of Surgery. New York: 1999.

10. Amir LR, Becking AG, Jovanovic A, Perdijk FB, Everts V, Bronckers AL. Vertical distraction osteogenesis in the human mandible: a prospective morphometric study. Clin Oral Implants Res 2006; 17 (4): 417-425.

11. Chin M, Toth BA. Distraction osteogenesis in maxillofacial surgery using internal devices: review of five case. J Oral Maxillofac Surg 1996; 54: 45-53.

12. Hidding J, Lazar F, Zoller JE. The vertical distraction of the alveolar bone. J Cranio Maxillofacial Surg 1998; 26 (Suppl I): 70-71.

13. Saulacic N, Gandra Vila P, Somozana Martin M, Garcia AG. Distraction osteogenesis of the alveolar rides: a review of the literature. Med Oral 2004; 9: 321-327.

14. Ross R, Raines E, Bowen-Pope D. The biology of platelet-derived growth factor. Cell 1986; 46: 155-169.

15. Cillo JE Jr, Gassner R, Koepsel RR, Buckley MJ. Growth factor and cytokine gene expression in mechanically strained human osteoblast-like cells: implication for distraction osteogenesis. Oral Surg Oral Med Oral Pathol Oral Radiol Endod 2000; 90: 147-154.

16. Robiony M, Toro $\mathbf{C}$ et al. Osteogenesis distraction and platelet-rich plasma: combined use in restoration of the severe atrophic mandible. Preliminary results. J Oral Maxillofac Surg 2002; 60: 630-635.

17. Yazawa M, Kishi K, Nakajima H, Nakajima T. Expression og bone morphogenetic proteins during mandibular distraction osteogenesis in rabbit. J Oral Maxillofac Surg 2003; 61: 587-592.

18. Meyer U, Kleinheiz J, Joos U. Biomechanical and clinical implication of distraction osteogenesis in craniofacial surgery. J Cranilo-Maxillofac Surg 2004; 32: 140-149.

19. Ggreenlagh D. The role of growth factors in wound healing. J Trauma 1996; 41: 159-167.

Received June 11, 2010. Accepted September 20, 2012. 